\title{
Factors Contributing to Low Productivity and Food Insecurity in Bungoma County, Kenya
}

\author{
Mary Stella Wabwoba* \\ Centre for Disaster Management and Humanitarian Assistance (CDMHA), Masinde Muliro University of Science and Technology (MMUST), Kenya
}

Received: November 10, 2017; Published: December 01, 2017

*Corresponding author: Mary Stella Wabwoba, Centre for Disaster Management and Humanitarian Assistance (CDMHA), Masinde Muliro University of Science and Technology (MMUST), Kakamega, Kenya, Tel: 254715210 135; Email: wabstella@yahoo.com

\begin{abstract}
Food insecurity within households is a risk to people's livelihoods. If not addressed in good time it could results into a disaster that will require foreign intervention for that affected community. Households in Bungoma county of Kenya were noted to be vulnerable to food insecurity due to low productivity and this state threatened peoples livelihoods. The objective of this study was to examine the physical, economic, environmental and social factors that led to low food production in Bungoma County, Kenya. A cross-sectional survey design was used in the study and a cluster (multi-stage random) sample size of 384 households was selected. Tools used for data collection were questionnaires, interview guides, focus group discussions and observation checklists. Data was analyzed using descriptive and inferential statistics. The study found that land size was small; the road network was poor and disorganized market systems. The cost of farm inputs was high as well as high poverty levels.

Climatic variability affected crops and animal production. Social support, traditional beliefs and culture which discriminated against women were key risk factors that contributed to low farm production, making households vulnerable to food insecurity. Based on the findings, the study concluded that low farm productions were attributed to physical (Poor road networks and small land size), economic (poverty and high cost of farm inputs), environmental (climate variability and deforestation) and Social (cultural belief and negative attitude) factors. The study recommended that costs of farm inputs should be subsidized, improve road network system and sensitize people on positive cultural practices and attitude change to allow both gender participation on issues of food security.
\end{abstract}

Key words: Farm productivity; Household food insecurity; Bungoma County

\section{Introduction}

\section{Background}

Food is a basic necessity of life. It is a basic means of sustenance and key for healthy and productive life. If Kenya is to continue to cut down on health costs and compete in a global economy, it should ensure adequate food security and nutrition within households. Food insecurity within households is a risk to people's livelihoods. If not addressed in good time it could result into a disaster that will require foreign intervention for that affected community. The economic development of any nation is dependent on the productive capacity of human resources which is however a function of how well fed they are. Poor farmers have little or no access to credit, particularly short-term seasonal credit for farming Audsley et al. [1]. Under such circumstances, households lack economic capacity and therefore are at a risk of being vulnerable to food insecurity. Crucial information on the type of interventions that can be most effective in increasing productivity, reducing hunger, targeting the most needy, informing preparedness and developing contingencies is lacking in most communities in Kenya Lautze et al. [2].

\section{Problem Statement}

Available literature indicates that Bungoma County is food insecure and also records a poverty index of $52.9 \%$ compared to the National index of $46 \%$, while the food poverty stands at $43 \%$ KNBS [3]. There is documentary evidence that Bungoma County has many stakeholders dealing with food security issues being led by the County Government GOK [4]. This would give an impression high production and food sufficiency at household level but it is not the case. Food situation reports dating way back to 2011, show insufficient food stocks among households in Kenya GOK [5]. Records of studies done in Bungoma county revealed household food insecurity NALEP [6], Muyesu [7], KARI [8] and Ndienya et al. [9]. Many families in Bungoma County take one meal a day, in contrast to the recommended three meals per day UNICEF [10]. Due to this controversy, the study was set up with the objective to examine factors that led to low productivity within households, making them vulnerable to food insecurity despite the County's interventions. 
Objective: The objective of this study was to examine physical, economic, environmental and social factors that led to low productivity and made households vulnerable to food insecurity in Bungoma County, Kenya

Contribution to the Field: The study will give recommendations to guide policy makers on issues of food security. This paper contributes to the knowledge bank important for scholars. It is arguable that findings of this study with a focus on Bungoma County will inform similar studies in other counties in the entire country.

Significance of Work: The outcome of the study will guide decision-makers at all levels in formulating food policies. Reliable and timely information on the incidence and causes of low productivity, food insecurity and malnutrition will be documented. Recommendations from the study is expected to assist households understand the crucial factors of production and risks of food insecurity and be able to appropriately plan their farming schedules.

\section{Research Methods and Design}

Materials: The study targeted household heads whose food security depended on farming. Community groups (women groups, men groups, youth groups and self-help groups) were targeted for focus group discussions. Opinion leaders, Non-Governmental Organizations, Community Based Organizations/Non-State actors, Faith Based Organizations and Government officials were selected as key informants.

Setting: This study was done in four sub-counties of Bungoma County; they included Bumula, Bungoma West, Mt. Elgon and Bungoma North. The County is located on the Southern slopes of Mt. Elgon, and lies between latitude $0^{0} 28^{1}$ and latitude $1^{0} 30^{1}$ North of the equator, and longitude $34^{0} 20^{1}$ East and $35^{0} 15^{1}$ East of the Greenwich Meridian.

Procedure: The research work adopted a cross-sectional survey research design and the variables examined were physical, environmental, social and economic factors. The population for the study was household heads, key informants and formal organized groups. A cluster (multi-stage random) sample size of 384 households- calculated using a formula from the book of Mugenda [11] was selected from household's population of 1,553,655 KNBS [12]. This study utilized both primary data collected from the field and secondary data from archival sources. Data was collected using semi-structured questionnaires administered to the selected household heads. Four (4) Focus Group Discussions were held and each group was composed of eight to twelve (8-12) members of mixed gender. Twenty (20) key informants purposely chosen from opinion leaders, Government departments, Faith based organizations, Non-governmental organizations were interviewed. More information was obtained from observation checklists $[13,14]$.

Analyses: The quantitative data were organized, coded and edited by a process called data cleaning Punch [15-17]. The statistical package for social sciences (SPSS) was used to analyze data. Two analyses were made. Descriptive analyses was done by use of means, modes, standard deviations, variance, percentages, and frequencies) while inferential analyses was by use of chi-square test and Spearman rank order correlation analysis.

\section{Results and Discussion}

\section{Physical Factors and Vulnerabilities to Food Insecurity}

Various physical factors were identified as contributors to low productivity. These included small land size for farming, non use of fertilizer and certified seeds. The soil was infertile and this led to low yields, poor infrastructure, and disorganized marketing system [18]. Chi-square tests revealed a significant relationship between physical factors and production levels in the county $(p$-value $=0.035$; $<0.05$ ). It was also established that markets were few and far apart from farmers. The distribution of farm produce outlet included; farm gate level, neighbors, local or open markets and others. International markets fetches better prizes but unfortunately, all households interviewed had no idea of existence of export market. Very little produce was sold to supermarkets, meaning low incomes that could not enable farmers to purchase certified seeds or other food items not produced on the farm $[19,20]$. The seasonal roads as well as lack of means of transport made farmers to sell their produce at low prices on the farm. Besides this, farmers did not have government permits and certificates of operation to enable them penetrate the supermarkets in the country.

\section{Economic Factors}

In order to earn a living and be food secure households engaged in the following activities: Dairy production, maize farming, horticulture, banana farming and petty trade. Most of the households depended on farming with some shifting from subsistence to business farming to raise income. Similar views were found by Makhanu et al. [21] working in the same region; this shift in attitude to do farming as a business reflects current trends of blending specialization and diversification to reap optimal benefits by smallholder farmers. This was also observed by similar studies as captured by government policy initiatives in Agriculture GOK [22]. The economic factors that contributed to low productivity and food insecurity were listed as high levels of poverty and high cost of farm inputs. Due to high cost of farm inputs like fertilizers and certified seeds, majority of the farmers planted uncertified maize seeds (number name) and without fertilizer. As a result of planting uncertified seeds, the cereal yields were so low that it hardly sustained a household for three months after harvest. Horticulture farming was affected due to non-use of chemicals to control pests and disease [23-25].

\section{Environmental Factors}

Environmental factors contributing to food insecurity were found to be natural calamities like drought, floods, hailstones and inadequate / unreliable rainfall. Crops on farms were at the risk of natural calamities like hail stones [26-28]. Too much rainfall led to floods which damaged both properties and livelihoods. Human activities like cutting of trees led to deforestation and this resulted into soil erosion. Erosion made soil unproductive as the soil nutrients are washed downstream, hence food insecurity for such households. Other factors established were pests and 
disease outbreaks which were a risk to both crops and animals [29]. This finding is comparable to a study done by Ahmed et al. [30], which revealed that increasing vulnerable environmental conditions such as diminished biodiversity, soil degradation or growing water scarcity can easily threaten food security for people dependent on the products of the land, forests, pastures, and marine environments for their livelihoods. These findings also support Kenya Government recommendations for adapting to climate change like; conservation farming, right land use practices that reduce emissions of greenhouse gases GOK [31].

\section{Social Factors}

A key social factor contributing to vulnerability was the gender of the household head. The study established that $80 \%$ households were headed by men while $20 \%$ were women. All decisions in the household were made by men. In many cases men were found to be the cause of food disasters in their own homes. Women had no say in decision making concerning food issues where men were heads [32-34]. Men made final decisions in relation to land allocation for different crops, when to market farm produce and the use of cash from sale of farm produce. The study further revealed that women were in the same category with children, so they could not be allowed to make final decisions in the households. One Man, during focus group discussion quoted the Holy Bible (Genesis 2:18) [35] where he said 'women were made to assist men), therefore they should always be subordinates to us'. This notion made households vulnerable to food insecurity as productive ideas from women may not be adopted. The findings were similar to the study done by Lautze et al. [2] who found out that positive traditional value, customs and ideological beliefs contributed to social vulnerability of any given household.

Focus group discussions recorded that culture prohibited working on the farm during bereavement and this contributed to low productivity incase funeral occurred during planting season. Farming activities may be stopped for periods exceeding three weeks. This can be crucial as even a small period of time lost affects agricultural production Africa Progress Report [36], Delgado [37]. Laziness, idleness among the youth and theft of farm produce while in the farm and store were mentioned as contributing factors to food insecurity. Key informants quoted lack of knowledge on production and storage as factors making households vulnerable to food insecurity. This was also revealed by household interview results, where $61 \%$ of the household heads only attained primary level of education, meaning they were limited in knowledge and the level of understanding of new farming technologies [38,39].

\section{Conclusion and Recommendations}

Farm production by Households in Bungoma County were found to be low and hence making them vulnerable to food insecurity because of the following factors; physical (Poor road networks and markets), economic (poverty and high cost of farm inputs), environmental (climate variability and deforestation) and Social (cultural belief and negative attitude). The study recommended that the County Government of Bungoma should subsidize costs of farm inputs and make it accessible to farmers, the road network system should be improved to ease transportation to access markets for farm produce, people should be sensitize on positive culture practices and attitude change to allow both gender participation on issues of food security.

\section{References}

1. (2015) Africa Progress Report 2015. Power, people, and planet: seizing Africa's energy and climate opportunities.

2. Ahmed A, Quisumbing A, Nasreen M, Hoddinott J, Bryan E (2010) Comparing food and cash transfers to the ultra-poor in Bangladesh, IFPRI Research Monograph 163. Washington DC: International Food Policy Research Institute, USA.

3. Audsley B, Halmem R, Balzer N (2010) Comparing cash and food transfers: A Cost-benefit analysis from rural Malawi, in Revolution: For food aid to food assistance. Rome: World Food Programme p. 14.

4. Alderman H, Hague T (2006) Counter cyclical safety nets for the poor and vulnerable, Food Policy 31: 372-383.

5. (2002) CARE 2003, Household Livelihood Security Assessments: A Toolkit for Practitioners. CARE USA, Atlanta: Clarendon Press, Oxford. pp. 126-127.

6. (2010) CMDRR 2010, Building Resilient Communities. A training manual on Community Disaster risk reduction.

7. Cromwell E, Kyegombe N (2005) Food security options in Malawi: good neighbours make good friends? pp. 152-154.

8. De Janvy A, Sadoulet E (2011) Subsistence farming as a safety net for food-price shocks 21(4-5).

9. Dercon S Ed (2005) Insurance against Poverty, UNU-WIDER Studies in Development.

10. (2010) FAO 2010, the state of food insecurity in the world. Rome: FAO. W Genesis 2:18, Holy Bible. New International Version.

11. (2007) Government of Kenya 2007, National food security and Nutrition policy sessional paper. Nairobi, Government Printers, Nairobi Kenya.

12. (2011) Government of Kenya 2011, National Food and Nutrition Security Policy, 2011. Nairobi, Government Printers, Kenya.

13. (2011) Government of Kenya 2011, Agriculture Sector Development Support Programme, Project Document. Nairobi, Government Printers, Kenya.

14.(2013) Government of Kenya 2013, Bungoma County Integrated Development Plan 2013-2017. Nairobi, Kenya: Government Printers.

15. (2013) KARI 2013, Ministry of Agriculture, Livestock and Fisheries and Agricultural Sector Development Strategy Programme (ASDSP). Household Baseline Survey, Bungoma, and County Nairobi, Government Printers, Kenya.

16. Karina F, Wambua MA (2011) March, Impact of the economic stimulus programme and long-term prospects for food security.

17. (2009) KNBS 2009, Population and Housing Census, Bungoma County projections. Nairobi, Government Printers, Kenya.

18. (2010) KNBS 2010, Kenya National Census report, 2009. Nairobi, Kenya: Government Printers pp. 319-325.

19. Lambden J, Receveur O, Marshall J, Kuhnlein H (2006) Traditional and market food access in the Arctic is affected by economic factors. Int J Circumpolar Health 65(4): 331-340.

20. Lautze S, Y Acob Aklilu, Angela Raven-R Oberts, Helen Young, Girma Kebede, et al. (2003) Risk and Vulnerability in Ethiopia: Learning From the Past, Responding to the Present, Preparing for the Future. Washington DC, USA. 
21. Lustig N, Carola Pessino, George Gray Molina, Wilson Jimenez, Ernesto Yanez, et al. (2012) Fiscal policy and income redistribution in Latin America: Challenging Managed Disaster Risk Reduction. Geneva

22. Makhanu FN, Kiptarus E, Kiongera F, Wamalwa CM, China SS, et al. (2012) Impact of Specialization and Diversification reengineering strategies on farm and off farm activities for sustainable Food security in Kenya.

23. Muchiri J (2015) Outrage over granny jailed for contempt. The Standard. Nairobi, Kenya: Standard Media

24. Mugenda AG (2008) Challenges Facing Mobile Schools among Nomadic Pastoralists: A Case Study of Turkana County, Kenya. Social Science Research. American journal of educational research 4(1): 22-32.

25. Muyesu (2013) the impact of Tobacco farming on Household food security in Bungoma County. Unpublished Master's Thesis at MMUST, Kenya.

26. NALEP (2012) Ministry of Agriculture NALEP impact evaluation report. Nairobi, Kenya: Government printers.

27. Ndienya Tom, Obama Rajab, Wamalwa Isaac (2013) Bungoma Food security assessment report, Ministry of Agriculture, Livestock and Fisheris, Kenya.

28. Neondo (2013) Kenya-Urban farming Policy.

29. Punch KE (2003) Survey Research: The Basics. Sage Publication, London.

30. Ramiro L, Da S (2009) Comprehensive Food Security \& Vulnerability Analysis Guidelines. United Nations World Food Programme, Rome, Italy.
31. (2015) Sendai framework 2015, Sendai Framework for Disaster Risk Reduction 2015-2030 p. 4-25.

32. Swindale A, Bilinsky P (2006) Development of a Universally Applicable. Household Food Insecurity Measurement Tool: Process, Current Status, and Outstanding Issues. The journal of nutrition 136(5): 14495-14525.

33. (2013) Food and Nutrition Technical Assistance (FANTA) Project \& Academy for Educational Development.

34. Tessa M (2007) Japan's Comfort Women: It's time for the truth (in the ordinary, everyday sense of the world). The Asia Pacific Journal 5(3)

35.(2009) UNICEF 2009, Determinants of malnutrition in children: A conceptual Framework.

36. (2004) UNISDR 2004, Hyogo framework for action 2005-2015: Office for Disaster Risk Reduction (UNISDR), Geneva, Switzerland.

37. (2007) UN WFP 2007, Hunger and health, United Nations world food programme. World Hunger Series, Earth scan

38. (2009) WFP 2009, Comprehensive Food security and Vulnerability Analysis guidelines ( $1^{\text {st }} \mathrm{edn}$.) Rome, Italy.

39. (2006) World Bank 2006, Hazards of Nature, Risks to Development: An IEG Evaluation of World Bank Assistance for Natural Disasters. Washington, DC: World Bank, Independent Evaluation Group, 2006, USA.

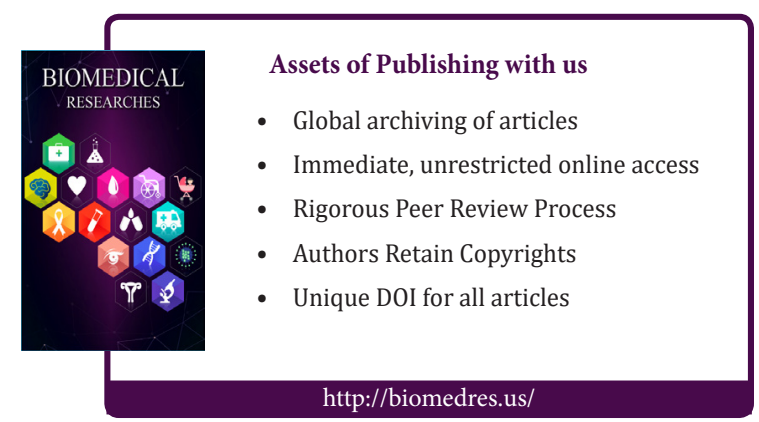

